DOI: $10.20472 / S S .2016 .5 .3 .001$

\title{
AN EMPIRICAL STUDY ABOUT A DIFFUSION OF AUTOMATED EXTERNAL DEFIBRILLATOR AND SOCIAL CAPITAL
}

\section{YURIKO ISADA, FUMIHIKO ISADA}

\begin{abstract}
:
The objective of this research is to clarify empirically about the relationship of a diffusion of a use of Automated External Defibrillator (AED) and social capital. If AED are continually not utilized $\square$ by bystanders in an effective manner, then a large amount of public expense which is supplied to an installation and training course of AED is wasteful. In this research, the hypothesis that rich social capital raises the consciousness to a use of AED was formed. As a methodology, the questionnaire to 1000 ordinary citizens was carried out. In conclusion, the effort towards rich social capital is useful to improvement in the ratio of lifesaving by using AED.
\end{abstract}

\section{Keywords:}

Automated External Defibrillator, Social capital, first-aid lifesaving, Bystanders, questionnaire

JEL Classification: $118, \mathrm{Z13}, \mathrm{H} 00$

\section{Authors:}

YURIKO ISADA, Kwansei Gakuin University, JAPAN, Email: yuriko@kwansei.ac.jp FUMIHIKO ISADA, Kansai University, Japan, Email: isada@kansai-u.ac.jp

\section{Citation:}

YURIKO ISADA, FUMIHIKO ISADA (2016). An empirical study about a diffusion of Automated External Defibrillator and social capital . International Journal of Social Sciences, Vol. V(3), pp. 1-16., 10.20472/SS.2016.5.3.001 


\section{Introduction}

In Japan, the placement of the automated external defibrillator (AED) has been advanced since its use by non-medical workers was approved on July 1,2004. The total sales of AEDs in all of Japan in 2004 were 6,701 sets (H. Kondo, 2012). In 2014 the total became 636,007 sets (Japan Heart Foundation, 2016), increasing by 95 times in ten years. AEDs installed in fire departments total 15,151 sets $(2.4 \%)$, in medical institutions, 104,721 sets $(16.5 \%)$, and in public facilities, 516,135 sets (81.2\%). By 2016, 1.37 public-access AEDs were installed per square kilometer, amounting to 4.05 AEDs per 1,000 persons (Japan Heart Foundation, 2016). According to Kitamura et al. (2010), when the number of public-access AEDs increased from less than one per square kilometer to four or more, the mean time to electroshock was reduced from 3.7 to 2.2 minutes, and the annual number of patients per 10 million populations who survived with onemonth minimal neurologic impairment increased from 2.4 to 8.9. The effect of increasing publicaccess AEDs is clear from increasing patients who survived with the one-month minimal neurologic impairment.

The number of the cases witnessed by ordinary citizens is 25,255 among the cardiogenic cardiopulmonary arrest patients for whom emergency conveyance was done during 2014, and among those were $13,679(54.2 \%)$ cases in which ordinary citizens executed cardiopulmonary resuscitation (CPR). Of those, the number in which defibrillation was performed using an AED is 1,030 persons (4.3\%) (Fire and Disaster Management Agency, Ministry of Internal Affairs and Communications, 2015). In more than half the cases, CPR was performed by a person who happened to be at the emergency scene (a bystander), and this is increasing every year. Although the placements of AEDs are increasing quickly, the use of the devices by bystanders has only slightly increased and still remains at a low level. The initial costs of AEDs are 300,000 yen to 500,000 yen, and the maintenance cost is 50,000 yen to 80,000 yen in five years. A study about more effective AED placement is needed, since the expenditures for placing and maintaining AEDs are useless if the AED is not fully utilized.

The lifesaving effect is noteworthy when a bystander who witnesses a person in cardiopulmonary arrest administers defibrillation using an AED, as compared to cases where an AED is not used. One study noted that after a bystander executed defibrillation using an AED, the number of onemonth survivors was $519(50.4 \%)$ and the number of persons who return to normal life one month later was $446(43.3 \%)$. Meanwhile, when CPR was administered by a bystander, there were 2,016 survivors $(15.4 \%)$ after one month and the number of persons who return to normal life one month later was $1,476(10.8 \%)$. When CPR was not executed by a bystander, the number of onemonth survivors totaled $976(8.4 \%)$ and the number of persons who return to normal life one month later was 496 (4.3\%). In cases where a bystander executed defibrillation using an AED, as compared execution of CPR by bystander, was about 3.3 times, and the rate of return to normal life one month later was about 4 times. In cases where a bystander executed defibrillation with the use of public-access AED was about 6 times, as compared CPR which was not executed by bystander, and the rate of return to normal life one month later was about 10.1 times (Fire and Disaster Management Agency, Ministry of Internal Affairs and Communications, 2015). The average arrival time of an ambulance in Japan is 8.6 minutes, and the rate of lifesaving falls 7 to $10 \%$ for every minute a person is untreated for cardiac arrest (Japan Medical Association, 2011). 
Whenever AED use is delayed for one minute, the percentage of those who can make a comeback to normal life in one month falls $9 \%$ (Kitamura et al., 2010).

According to a public opinion survey on firefighting (Fire and Disaster Management Agency, 2011) implemented in Japan, many persons responded that the potential responsibility for errors or the risk of infection are reasons for failing to execute first aid. It would be helpful to relieve worries and misunderstanding by disseminating correct knowledge and encouraging a helpful attitude. The firefighting headquarters and fire departments were implementing a lifesaving emergency course across the country based on the implementation guideline about promoting enlightening and dissemination activities of first aid education (Fire and Disaster Management Agency, 1993). After the Great East Japan Earthquake, the Tokyo Fire Department began expanding first aid and lifesaving training, including AED use, to $20 \%$ of the daytime population (about 2,240,000 people), in order to raise the execution rate and quality of first aid given by bystanders.

The structure of this paper is as follows. Section 2 reviews research on the state of AED use, then addresses the issue of social capital and discusses the relationship between health and social capital. Section 3 states the hypothesis concerning the relationship between bystander use of AED defibrillation and social capital, and the verification method is shown. Section 4 describes questionnaire results, verifies the relationship between bystander AED use and social capital, and puts forth arguments concerning the policy for the promotion of utilization of AED. The result obtained in this thesis is summarized in Section 5.

\section{Previous research}

The effect of using AEDs in lifesaving medicine is extensive, and it is important to promote the use of AEDs at the time of bystander CPR. Much research exists on the placement of AEDs. Mitamura $(2008$; 2012) has pointed out the lack of political and strategic viewpoints in AED placement, and asserts that the number of available AEDs still runs short. In the USA, the onset state of sudden cardiac arrest in public or indoor athletic facilities was surveyed, and it has been studied how AEDs should be arranged (Becker et al., 1998; Page et al., 2013). In Japan, the disposition of AED placement is left to independent efforts by self-governing bodies or corporations, and guidelines for proper placement of AEDs were barely addressed concerning self-governing bodies in 2013 (The Ministry of Health, Labour and Welfare, 2013). It is said most instances of sudden cardiac arrest occur in a house. Bardy et al. (2008) conducted a large-scale study on AED placements in houses. They found no difference in mortality between the group which had installed AEDs in their houses and the group which did not install AEDs, and they concluded that the presence of AEDs in houses is not effective. This may be because it was rare to have witnesses to cardiac arrest in a house, and people in the house were not able to use the AED in many cases because of advanced age. It is said that about $70 \%$ of cardiac arrests in Japan occur in homes. Endoh et al. (2011) compared the effectiveness of AED placement in homes to the effectiveness of AEDs in convenience stores and police facilities in Niigata Prefecture. As a result, it was shown that the present condition of AED placement is insufficient in homes when cardiac arrest occurs, but the availability of AEDs in convenience stores or police facilities is effective. Although the availability of AEDs is still a problem, after allowing non-medical laymen to use the devices, the benefits of AEDs progressed quickly in 12 years, and it can be said that the placement state of AEDs has improved sharply. However, an AEDs do not show 
performance commensurate with the cost of installing and maintaining AEDs because AEDs of placement are not utilized enough. Promoting the use of AEDs necessitates countermeasures, such as simplification of the content of emergency lifesaving courses and holding emergency lifesaving courses towards the younger age group (Page et al., 2013).

The use of an AED at an emergency scene requires the presence of two or more bystanders. When sudden cardiac arrest is witnessed, one person is needed to perform CPR while another calls emergency responders and gets the AED. Collaboration between people who may be strangers who happened to be at the emergency scene is indispensable, and it may be important that relationships are built in the society so that people act cooperatively. Putnam et al. (1993) have described social capital as cooperative activity among people that raises social efficiency. According to a definition by the Organization for Economic Cooperation and Development (OECD), social capital comprises 'networks together with shared norms and values and understandings that facilitate co-operation within or among groups' (Kelley, 2007). According to Putnam et al. (1993), the components of social capital are 'trust', a 'norm', and a 'network'. The quest of a virtuous circle of rich human relations and civic activities calls upon 'association and interchange', 'trust', and 'social participation' as components of social capital (Social Policy Bureau of the Cabinet Office, 2003). Kaneya (2008) surveyed literature that addressed the elements contributing to the formation of social capital and the methods of measuring it, and then analysed the findings. traditional neighborhood associations and modern independent associations were examined, and it was shown that a network of traditional neighborhood associations type relationships has a good influence on the performance of the social economy and living environment. However, according to Pearce and Smith (2003), intervention in a community for improving social capital may sometimes be ineffective, create resentment, and overload community resources.

About the relevance of social capital indices and health outcomes, most research studied Western societies, while northeastern Asian countries, and particularly Japan, were hardly studied until now (Fujisawaa et al., 2009). Inoue et al. (2013) performed a literature search of the research trend on the topic of social capital and health in Japan. The research on social capital and health in Japan was activated after the 2009 fiscal year. In the 34 of the 54 surveyed papers a distinct positive correlation can be seen between social capital and health indicators. However, many of the studies were limited to particular cities, towns and villages or demographic groups such as elderlies, and the necessity for broader surveys is pointed out. Mamada (2010) surveyed 19 studies that actually measured and analysed the relevance of social capital to health indicators in Japan. As a result, the significant relevance with a health indicator was reported for 'a sense of trust', the 'reciprocity norm', and the 'participating organization number', which are the indices mostly used in measuring social capital in almost all literature. Murayama et al. (2014) surveyed the literature in the peer-reviewed PubMed database and analysed from many sides the effect of social capital on the health. As a result, the verification of social capital's effect on health is still incomplete, and to regard social capital as a tool to promote health, the study pointed out that further empirical research was required. Rocco et al. (2011), as a result of analysing the data of the European Social Survey for 26 European countries and the EU Statistics Bureau, revealed strong proof that social capital and health are mutually and cyclically related. Nieminen et al. (2013), in a survey in Finland, made clear that social participation and social networks are related to all health behaviours. And regardless of the social place, people with a high level of social 
capital felt healthy physically and mentally. In Japan, Nagatani (2012) analysed the relationship of social capital and lifestyle to health in a survey of the health promotion project of Yamaguchi Sanyo Onoda, and it became clear that social capital and lifestyle affected health to the same extent.

\section{The hypothesis and the verification method}

The objective of this research is to discuss measures for promoting the willingness of bystanders to perform defibrillation using AEDs. It assumes that if a person who happens to be at an emergency scene tries to perform emergency lifesaving because of the desire to help someone, this is considered to correspond to the 'norm' factor of social capital. According to research on the relationship between social capital and health inside and outside Japan, social capital is related to health indicators and a subjective sense of health. Studies reviewed concerning the relevance of social capital and civic activities shows that civic activities based on a network of traditional neighborhood associations have a better influence on the formation of social capital.

From the above, the following was derived as a hypothesis.

1) Social capital is related to whether a bystander executes defibrillation using an AED.

2) The knowledge of AEDs and a consciousness toward health are related to whether a bystander executes defibrillation with an AED.

As the method of verification, a questionnaire was given to ordinary citizens. The instrument included questions about intent to use an AED for defibrillation at the site of first aid for life saving, recognition of an AED and the understanding of its use, whether the respondent had taken an emergency lifesaving course, their health consciousness, behavioural characteristic of an ordinary citizen to a social capital component. The component is trust, a norm, and a network.

Suzuki (2008) has identified 'network', 'social trust', and 'reciprocity' as factors of social capital. The evaluation criteria of 'network' include 'a neighbouring-related quality', the 'liveliness of a local community', the 'liveliness of a theme community', and 'the height of the political interest'. Elements of 'social trust' are 'the general trust of strangers' and 'the trustworthiness of the neighbourhoods'. 'Reciprocity' includes 'social support' and 'volunteer activity'. In executing a citizen opinion poll on the topic of health, Nagatani (2012) divided social capital into three elements: 'association and interchange', 'trust' and 'social participation'. The evaluation criteria of 'association and interchange' included 'participation in a hobby circle (a cultural group or sport group)' and 'participation in a religious related meeting'. Stated as the evaluation criteria of 'trust' were 'participation in a neighbourhood self-governing body collaborative work', 'participation in a school event or athletic meet', 'the existence of persons who can sympathize', 'people's existence admired generally', 'the existence of people who give advice', and 'the existence of people who take care of the sick'. The evaluation criteria of 'social participation' were 'participation in volunteer civic activities', 'the feeling of wanting to be helpful to someone', and 'a feeling that people generally want to be helpful'. Although each study classified the structure of social capital into three parts, they did not use the same scale to classify each factor. For example, Nagatani (2012) placed 'participation in a local activity' in the 'norm' classification, and other researchers (Nieminen, 2013) have included this with the 'network' . 
This study uses 'trust', 'norm', and 'network', which are the components of social capital as established by Putnam et al. (1993). Among items related to 'association and interchange', the item accompanied by a voluntary activity was classified into the 'norm' factor, and the other items were classified into the 'network' factor. Table 1 shows the rate scale of 12 items and the classification of social capital used by this research. The rate scale refers to the items in the literature reviewed.

\section{Table 1 The rate scale of social capital}

\begin{tabular}{|l|l|l|}
\hline \multicolumn{2}{|c|}{ Rate scale } & Element \\
\hline Q1_1 & The positive participation in the circle (cultural system) of a hobby. & Network. \\
\hline Q1_2 & The positive participation in the circle (sport system) of a hobby. & Network. \\
\hline Q1_3 & The positive participation in civic activities. & Network. \\
\hline Q1_4 & The positive participation in a religious related meeting. & Network. \\
\hline Q1_5 & The positive association with neighbouring people or local people. & Network. \\
\hline Q1_6 & The positive participation in a volunteer activity. & Norm. \\
\hline Q1_7 & $\begin{array}{l}\text { The positive participation in the collaborative work of a neighbourhood } \\
\text { self-governing body. }\end{array}$ & Norm. \\
\hline Q1_8 & The positive participation in a local festival or event. & Norm. \\
\hline Q1_9 & A feeling of wanting to be helpful to someone. & Norm. \\
\hline Q1_10 & A feeling that people generally want to be helpful. & Norm. \\
\hline Q1_11 & Existence of persons who can be consulted about a troubles or worries. & Trust. \\
\hline Q1_12 & General trust of strangers. & Trust. \\
\hline
\end{tabular}

\section{$4 \quad$ Research results}

The questionnaire was implemented from June 29 to June 30, 2015, using the Internet research service of Macromill, Inc. The subjects who were sent the questionnaire were Macromill members. The survey subjects were targeted to uniformly represent men, women and different ages. Table 2 shows the distribution among districts. The survey was sent to 1,030 people, and analyses were conducted among 978 respondents who said they were familiar with an AED. The analyses were carried out using the SPSS statistics software package of the IBM Corp.

\section{Table 2 Regional distribution of respondents}

\begin{tabular}{|l|r|r|}
\hline \multicolumn{1}{|c|}{ Area } & Number & \multicolumn{1}{c|}{$\%$} \\
\hline Hokkaido & 58 & 5.63 \\
\hline Tohoku district & 63 & 6.12 \\
\hline Kanto district & 384 & 37.28 \\
\hline Chubu district & 167 & 16.21 \\
\hline Kinki district & 192 & 18.64 \\
\hline Chugoku district & 54 & 5.24 \\
\hline Shikoku district & 18 & 1.74 \\
\hline Kyushu district & 94 & 9.13 \\
\hline Total & 1030 & 100 \\
\hline
\end{tabular}

Table 3 provides the results for a question about whether the respondents had used an AED, showing that $98.2 \%$ of respondents had never performed defibrillation by AED. Respondents with four or more experiences totalled $0.4 \%$. Although they might be medical workers or firefighters, almost all the respondents of this questionnaire were ordinary citizens. Among the 978 
respondents, $13.4 \%$ 'strongly agree' with the use of AED defibrillation in an emergency, and $27.1 \%$ responded 'agree'. Less than a majority, $40.5 \%$, said they might try to perform defibrillation using AED in an emergency.

Table 3 The number of times of respondents used AED defibrillation

\begin{tabular}{|l|c|c|}
\hline The number of times respondents used AED defibrillation & Number & $\%$ \\
\hline 0 times & & \\
\hline 1 time & 772 & 94.96 \\
\hline 2 times & 22 & 2.71 \\
\hline 3 times & 7 & 0.86 \\
\hline 4 times or more & 1 & 0.12 \\
\hline Total & 11 & 1.35 \\
\hline
\end{tabular}

Table 4 details, by percentage of respondents, the reasons given for hesitating to use an AED. The main reasons for hesitating to use an AED are 'a lack of confidence that it would be executed well' and 'avoidance of trouble if it fails'. The percentage who responded that they 'strongly agree' or 'agree' to 'the lack of confidence that it would be executed well' was $73.7 \%$. And the percentage who responded that they 'strongly agree' or 'agree' to 'avoidance of trouble if it fails' was $62.1 \%$. Even if the respondent was familiar with the device, the percentage who responded 'I don't know the procedure' was $54.1 \%$, and $44.4 \%$ responded 'the installation location of AEDs is not known'. Table 4 Reasons for hesitating to use an AED in an emergency, by percentage of
respondents

\begin{tabular}{|l|c|c|c|c|c|}
\hline The reason for hesitating to use AED & $\begin{array}{c}\text { Strongly } \\
\text { Agree }\end{array}$ & Agree & Undecided & Disagree & $\begin{array}{c}\text { Strongly } \\
\text { Disagree }\end{array}$ \\
\hline I don't know the procedure. & 29.4 & 24.7 & 16.7 & 19.2 & 9.9 \\
\hline $\begin{array}{l}\text { A lack of confidence that it would be } \\
\text { executed well. }\end{array}$ & 37.0 & 36.7 & 11.8 & 8.9 & 5.6 \\
\hline I do not want to be concerned. & 9.6 & 22.9 & 31.7 & 24.4 & 11.3 \\
\hline Avoidance of trouble if it fails. & 26.9 & 35.2 & 20.4 & 11.2 & 6.2 \\
\hline $\begin{array}{l}\text { Time cannot be taken (I am } \\
\text { hurrying). }\end{array}$ & 6.7 & 14.0 & 39.7 & 24.9 & 14.6 \\
\hline $\begin{array}{l}\text { The installation location of AEDs is } \\
\text { not known. }\end{array}$ & 13.0 & 31.4 & 28.7 & 19.0 & 7.9 \\
\hline
\end{tabular}

Next, as a result of conducting the factor analysis by the maximum likelihood method in a promax rotation for every component of social capital, these were put together by one common factor regarding 'network' and 'trust'. The 'network' alpha coefficient is 0.801 and the internal consistency of the 'network' factor is satisfactory. The alpha coefficient of 'trust' was 0.549 . Two common factors were extracted concerning the 'norm'. The primary factor showed high factor loadings for the items concerning the behaviour of a norm, and the 2nd factor showed high factor loadings for the items concerning the consciousness of a norm. The primarily factor was named the 'behaviour' factor, and the 2nd factor was named the 'consciousness' factor. With the reliance scale of each subordinate scale, the alpha coefficient of the 'behaviour' factor was 0.806 , internal 
consistency was satisfactory and the alpha coefficient of the 'consciousness' factor was 0.588 . The factor which integrated the subordinate scale of the 'consciousness' factor and the subordinate scale of 'trust', which is a component of social capital, was assumed, and an alpha of 0.709 was obtained. Table 5 shows the mean, standard deviation (SD) and alpha coefficient. Table 6 shows the correlation between each subordinate scale. Network and norm (as behaviours) show a strong positive correlation.

Table 5 Average of subordinate scale, standard deviation and alpha coefficient

\begin{tabular}{|l|c|c|c|}
\hline & $M$ & $S D$ & $\alpha$ coefficient \\
\hline Network & 2.0406 & .81198 & 0.801 \\
\hline Norm (behaviour) & 2.2269 & 1.03538 & 0.806 \\
\hline Trust + norm (consciousness) & 3.4063 & .73206 & 0.709 \\
\hline
\end{tabular}

Table 6 Correlation of subordinate scales

\begin{tabular}{lccc}
\hline & Network & $\begin{array}{c}\text { Norm } \\
\text { (behaviour) }\end{array}$ & $\begin{array}{c}\text { Trust + norm } \\
\text { (consciousness) }\end{array}$ \\
\hline Network & - & $.811^{\star *}$ & $.354^{\star *}$ \\
Norm (behaviour) & & - & $.376^{\star *}$ \\
Trust + norm (consciousness) & & & - \\
\hline
\end{tabular}

${ }^{* *} p<.001$

A factor analysis was conducted for the rate scale of social capital, and it was combined to two common factors, 'positive network oriented' and 'trust' (Isada and Isada, 2016).

'The positive participation in a volunteer activity', 'the positive participation in the collaborative work of a neighbourhood self-governing body', and 'the positive participation in a local festival or event', which are the rate scales of a behaviour classified into the 'norm' in the rate scale of social capital, were classified into the 'positive network oriented' factor. 'A feeling of wanting to be helpful to someone' and 'a feeling that people generally want to be helpful', which are the rate scales concerning consciousness, were classified as 'trust' factors. It was analysed whether bystander AED defibrillation using two extracted common factors would be executed. Table 7 shows the subordinate scale of each factor. The mean of two subordinate scales of the rate scale of social capital was computed, and it was considered as the subordinate scale score. 'Positive network-oriented' subordinate scale scores were $(M=2.15$ and $S D=0.79)$. The subordinate scale scores of 'trust' were $(M=3.41$ and $S D=0.73)$. The alpha coefficient of the subordinate scale was as follows: 'positive network-oriented', 0.888, and 'trust', 0.709 ; the value of the alpha coefficient became the highest and the internal consistency of the subordinate scale became the highest. Table 8 shows the correlation between each subordinate scale. A significant positive correlation is seen between the two subordinate scales.

Next, the t-test was performed to analyse the difference in the execution state of bystander use of AED defibrillation. Table 9 and Table 10 show the mean, SD and t-test results. A significant difference was seen with $5 \%$ and $1 \%$ of significant probability between the group that uses an AED and the group that does not, regarding the subordinate scales of 'positive network oriented' and 'trust'. The group which executes AED defibrillation showed high scores in both 'positive network oriented' and 'trust'. 
Table 7 The factors and subordinate scale of social capital

\begin{tabular}{ll} 
Factor & Subordinate scale \\
\hline & The positive participation in civic activities. \\
The positive participation in the collaborative work of a neighbourhood \\
self-governing body. \\
The positive participation in a volunteer activity. \\
The positive participation in the circle (cultural group) of a hobby. \\
The positive participation in a local festival or event. \\
The positive participation in the circle (sport group) of a hobby. \\
oriented \\
The positive participation in a religious related meeting. \\
The positive association with neighbouring people or local people. \\
General trust of strangers. \\
A feeling that people generally want to be helpful. \\
A feeling of wanting to be helpful to someone. \\
Existence of persons who can be consulted about troubles or worries.
\end{tabular}

Table 8 The correlation between subordinate scales

\begin{tabular}{lcc}
\hline & Network & Trust \\
\hline Network & - & $0.394^{\star \star}$ \\
Trust & & - \\
\hline${ }^{\star \star} p<.001$ & &
\end{tabular}

Table 9 Mean, SD and t-test results according to AED use (positive network oriented)

\begin{tabular}{cccccccc}
\hline & \multicolumn{6}{c}{ Yes or no to AED use. } \\
\cline { 2 - 7 } & \multicolumn{3}{c}{ No } & \multicolumn{3}{c}{ Yes } & \multirow{2}{*}{$t$ value } \\
\cline { 2 - 7 } & $M$ & $S D$ & $M$ & $S D$ & & \\
\hline Positive network oriented. & 2.02 & 0.72 & 2.35 & 0.85 & 6.510 & $\mathrm{p}<.001$ \\
\hline
\end{tabular}

Table 10 Mean, SD and t-test result according to AED use (trust)

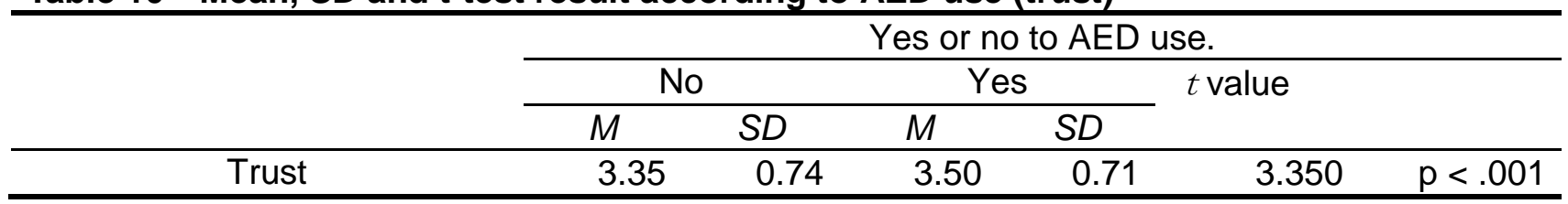

Table 11 shows the AED knowledge scale. These were put together by one common factor as a result of conducting a factor analysis. The common factor was named the 'knowledge' factor. The mean of the subordinate scale was computed, and it was considered as the subordinate scale score. Subordinate scale scores were $(M=2.28$ and $S D=0.90)$, and the alpha coefficient was alpha $=0.685$. 
Table 11 The rate scale of AED knowledge

\begin{tabular}{|l|l|}
\hline \multicolumn{2}{|c|}{ Rate scale } \\
\hline Q2_1 & Attendance at a lifesaving course every two to three years for skill retention. \\
\hline Q2_2 & The number of times of course attendance. \\
\hline Q2_3 & Viewing and listening to an animated film site about the directions for an AED. \\
\hline Q2_4 & The known number of AED installation locations. \\
\hline Q2_5 & The knowledge about the voice directions available when using an AED. \\
\hline
\end{tabular}

The t-test was performed to analyse the differences in the execution state of bystander AED defibrillation. Table 12 shows the mean, SD and t-test results. In the subordinate scale of 'knowledge', a significant difference was seen for $5 \%$ and $1 \%$ of a significant probability between the group which uses the AED and the group which does not. The group which executes defibrillation using the AED showed a high score in 'knowledge' .

Table 12 The mean, SD and the t-test results according to AED use (knowledge)

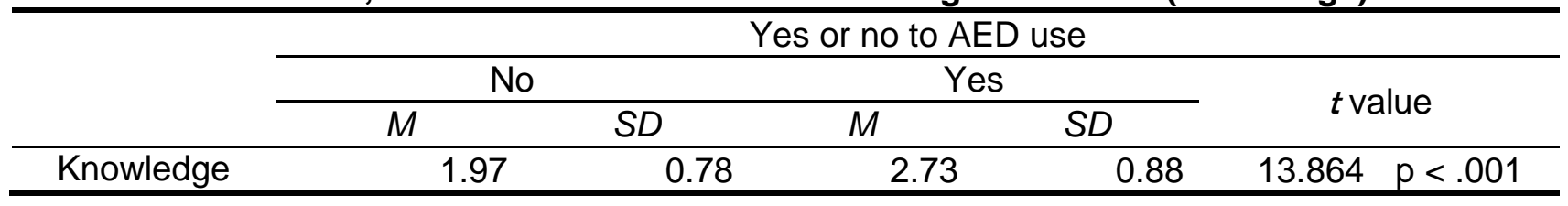

Table 13 The rate scale for health condition or health consciousness

\begin{tabular}{|l|l|}
\hline \multicolumn{2}{|c|}{ Rate scale } \\
\hline Q3_1 & $\begin{array}{l}\text { Positiveness of the health and medical service related activities of a self-governing body } \\
\text { or a town. }\end{array}$ \\
\hline Q3_2 & Usual health consciousness. \\
\hline Q3_3 & Confidence in health in comparison to peers. \\
\hline Q3_4 & Pressure on the household economy from medical or caregiving expenses. \\
\hline
\end{tabular}

Table 13 shows the rate scale for health condition or health consciousness. Although the factor analysis was implemented for the rate scale for health condition or health consciousness and common factor was obtained, the alpha coefficient is low (alpha $=0.575$ ), the reliance of the scale was not enough and the common factor was not approved. Therefore, the rate scale for health condition or health consciousness were analysed using the original rate scale items. The t-test was performed to analyse the difference in the execution state of bystander AED defibrillation. Table 14, Table 15, Table 16 and Table 17 show a mean, SD and t-test results. In the rate scale for health condition or health consciousness, the significant difference was seen for $5 \%$ and $1 \%$ of a significant probability between the group which uses AED defibrillation and the group that does not. The group which executes defibrillation using an AED showed a high score in all the items on the rate scale for health condition or health consciousness. 
Table 14 The mean, SD and the t-test results for AED use (Q3-1)

\begin{tabular}{|c|c|c|c|c|c|c|}
\hline & \multicolumn{6}{|c|}{ Yes or no to AED use. } \\
\hline & \multicolumn{2}{|c|}{ No } & \multicolumn{2}{|c|}{ Yes } & \multirow[t]{2}{*}{$t$ value } & \\
\hline & $M$ & $S D$ & $M$ & $S D$ & & \\
\hline $\begin{array}{l}\text { Positiveness of the health and medical } \\
\text { service related activities of a self-governing } \\
\text { body or a town. }\end{array}$ & 2.42 & 0.91 & 2.72 & 1.06 & 4.776 & $p<.001$ \\
\hline \multirow[t]{4}{*}{ Table 15} & & & 3_2) & & & \\
\hline & \multicolumn{6}{|c|}{ Yes or no to AED use. } \\
\hline & \multicolumn{2}{|c|}{ No } & \multicolumn{2}{|c|}{ Yes } & \multirow[t]{2}{*}{$t$ value } & \\
\hline & $M$ & $S D$ & $M$ & $S D$ & & \\
\hline Usual health consciousness. & 3.62 & 1.04 & 3.92 & 0.90 & 4.922 & $p<.001$ \\
\hline \multirow[t]{4}{*}{ Table 16} & Fot & 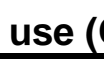 & 3_3) & & & \\
\hline & \multicolumn{5}{|c|}{ Yes or no to AED use. } & \\
\hline & \multicolumn{2}{|c|}{ No } & \multicolumn{2}{|c|}{ Yes } & \multirow[t]{2}{*}{$t$ value } & \\
\hline & $M$ & $S D$ & $M$ & $S D$ & & \\
\hline Confidence in health in comparison to peers. & 2.78 & 1.00 & 3.08 & 1.13 & 4.34 & $p<.001$ \\
\hline \multicolumn{7}{|c|}{ Table 17 The mean, SD and the t-test results for AED use (Q3_4) } \\
\hline & \multicolumn{5}{|c|}{ Yes or no to AED use. } & \\
\hline & \multicolumn{2}{|c|}{ No } & \multicolumn{2}{|c|}{ Yes } & \multirow[t]{2}{*}{$t$ value } & \\
\hline & $M$ & $S D$ & $M$ & $S D$ & & \\
\hline $\begin{array}{l}\text { Pressure on the household economy from } \\
\text { medical or caregiving expenses. }\end{array}$ & 2.57 & 1.11 & 2.8 & 1.13 & 3.117 & $\mathrm{p}<.001$ \\
\hline
\end{tabular}


Table 18 The correlation between AED use and each factor

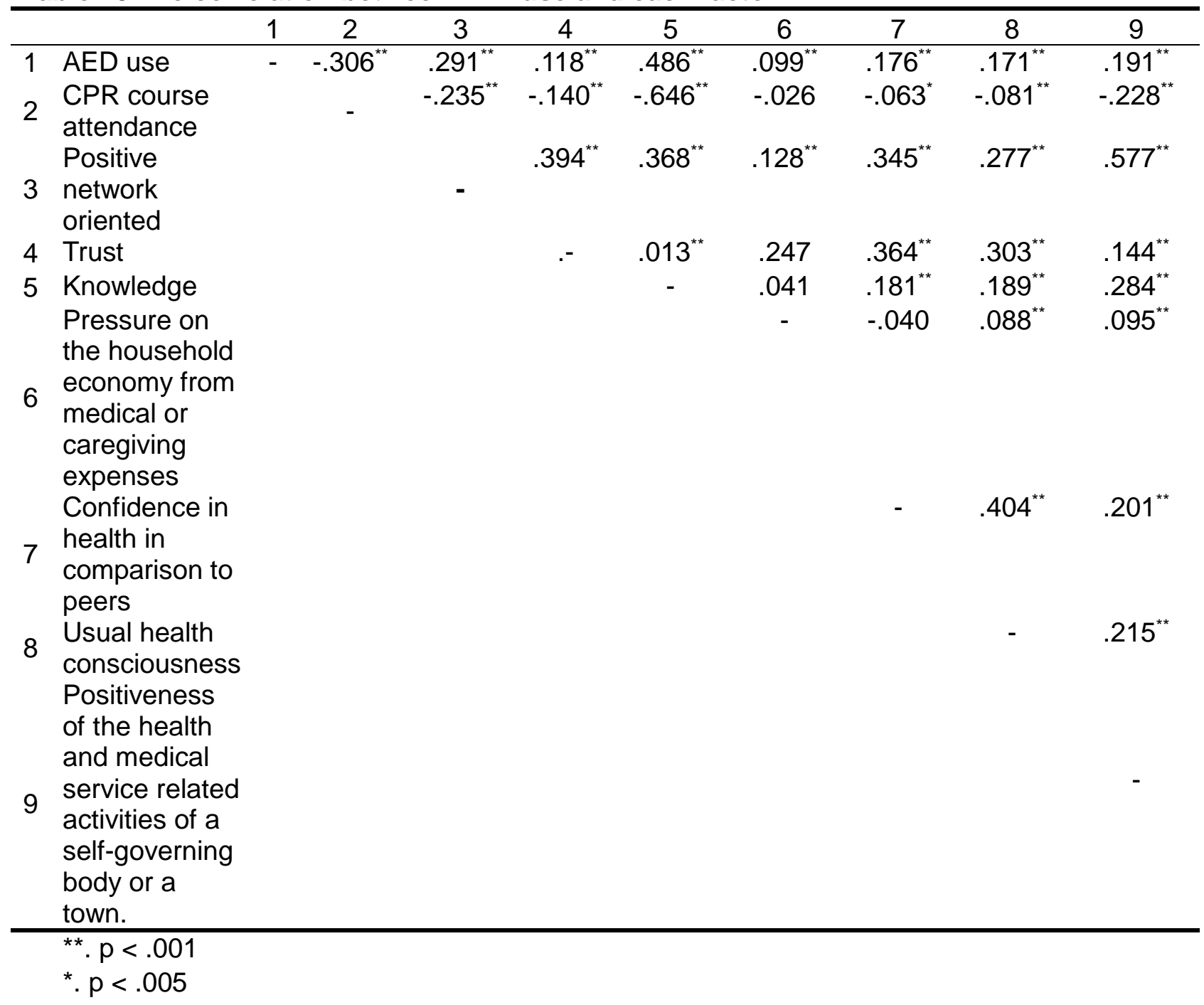

Table 18 shows the correlation of two factors of the rate scale of social capital, the factor of the knowledge scale over AED, the health condition or health consciousness scale, the number of times of course attendance, and the bystander use of AED defibrillation. Bystander use of AED defibrillation had a significant correlation, with a $1 \%$ level, to all the items. 'Attendance of a course' had a high correlation coefficient with 'knowledge' and 'positive network oriented' factors, and the correlation coefficient with trust feeling, health consciousness, and a sense of health investment burden was low.

\section{Discussion}

According to the precedent research, after approving non-medical worker use of $A E D$, the placement of AED progressed significantly; however, since AED is not used sufficiently, the necessity for a countermeasure which promotes the utilization of AED is highlighted. As an effective countermeasure, re-examination of the content of the course and an expansion of the coverage of courses, such as for younger age groups, is proposed. Table 19 shows the result of 
the t-test which examined the significant difference of the enforcement state of defibrillation using AED between a lifesaving emergency course attendee and a non-attendee. Between a lifesaving emergency course attendance group and a non-attendance group, there is a significant difference in the significant probability of five per cent and one per cent, and a high possibility that the lifesaving emergency course attendance group implemented the defibrillation using AED became obvious. It can be said also from the search results in this research that enforcement of a lifesaving emergency course is an effective countermeasure in the promotion of utilization of AED. Table 20 shows the result of the t-test which examined the significant difference of the enforcement state of the defibrillation using AED through the difference in the attendance time of a course. Between attendance of a lifesaving emergency course within two years and a nonattendance group, there is a significant difference in the significant probability of five per cent and one per cent, and a high possibility that the group which took the lifesaving emergency course within two years implemented the defibrillation using AED was shown. For an improvement in the enforcement ratio of defibrillation using AED by a bystander, it is important to build the scheme not only by encouraging attendance of a lifesaving emergency course but by periodically attending a course as an existing attendee. Furthermore, in this research, it became obvious that high knowledge and concern about AED-such as the recognition of re-attendance effectiveness, an AED animated film site, an installation location, and a precise use protocol other than attendance of a lifesaving emergency course-affect the enforcement of defibrillation using AED.

Table 19. The result of the mean, SD and t-test of a lifesaving emergency course attendee and a non-attendee (use of AED)

\begin{tabular}{|c|c|c|c|c|c|c|}
\hline & \multicolumn{6}{|c|}{ A lifesaving emergency course attendee and a non-attendee } \\
\hline & \multicolumn{2}{|c|}{ Non-attendee } & \multicolumn{2}{|c|}{ Attendee } & \multirow{2}{*}{\multicolumn{2}{|c|}{$\mathrm{t}$ value }} \\
\hline & $\mathrm{M}$ & SD & $\mathrm{M}$ & SD & & \\
\hline Use of AED & 2.91 & 1.04 & 3.49 & 1.07 & 8.626 & $p<.001$ \\
\hline
\end{tabular}

Table 20. The result of the mean, SD and t-test according to lifesaving emergency course attendance time (use of AED)

\begin{tabular}{|c|c|c|c|c|c|c|}
\hline & \multicolumn{6}{|c|}{ Lifesaving emergency course attendance within two years } \\
\hline & \multicolumn{2}{|c|}{ Non-attendee } & \multicolumn{2}{|c|}{ Attendee } & \multicolumn{2}{|c|}{$\mathrm{t}$ value } \\
\hline & $\mathrm{M}$ & SD & $\mathrm{M}$ & SD & & \\
\hline Use of AED & 3.39 & 1.04 & 3.95 & 1.09 & 4.681 & $p<.001$ \\
\hline
\end{tabular}

In the precedence research, it is pointed out that the abundance of social capital has a good effect on the improvement of efficiency in society, and it is said to consist of three factors: a network, a norm and trust. As a result of surveying the relevance of an enforcement of defibrillation using AED using the evaluation indicator of each factor well used in precedent research, two factors of a positive network-oriented and trust were extracted. The positive network-oriented factor contained the evaluation indicator for behaviour in terms of relationships, 
interchange, etc. among the networks and the norms which are the factors of social capital. The trust factor contained the evaluation indicator for consciousness of trust and the norms which are the factors of social capital. As a result of investigating the correlation between two factors and defibrillation enforcement using AED by a bystander, both were significant at the one per cent level, but the positive network-oriented correlation coefficient was high compared with the correlation coefficient of trust. Persons who may implement defibrillation using AED by a bystander are thought to be people who act within a positive network and attach importance to relationships with others. When people who act within a positive network and attach importance to relationships with others happen to be at the emergency scene, they may take positive action towards a sick person.

In the precedent research on social capital and health, it is indicated that social capital is connected with a health indicator and a sense of a subjective health. Also in this research, both the positive network-oriented factor and the trust factor were correlated with "confidence in health in comparison to peers" which is an evaluation indicator in respect of health. The positive network-oriented factor had the correlation with "positiveness of the health and medical service related activities of a self-governing body or a town", and the trust factor had the correlation with "usual health consciousness". Social capital relates to a health as pointed out also on the precedence research, but it can be said that not only the consciousness to a health but a practical positive activity is an important factor about an enforcement of the defibrillation which uses AED.

\section{Conclusion}

The objective of this research was to verify empirically the relationship between defibrillation using AED by a bystander and social capital. In addition, it discussed measures for promoting enforcement of defibrillation using AED by a bystander.

The hypothesis that enforcement of defibrillation using AED by a bystander was related to social capital was verified by the questionnaire. It was proved that the enforcement of defibrillation using AED by a bystander was deeply related to social capital. The persons who may implement defibrillation using AED by a bystander are aggressive people, positive in terms of network construction activities in society. When such people are at the emergency scene, positive behaving towards a sick person is assumed. In addition, the hypothesis that people who have knowledge of AED and people with a high concern of health implemented the defibrillation using $A E D$ was verified. Although knowledge of AED was an important factor regarding the use of AED, it became clear that not only concern about health but also behaviour was important.

The results of the research are as follows. In order to raise the enforcement ratio of defibrillation using AED by a bystander, it is important to use various media from various angles to take measures to raise knowledge of AED. In addition, it is important to urge periodical attendance of a lifesaving emergency training course. Furthermore, it is important to support the behaviour of people in network construction and to improve the circumstances of local society so that people behave positively. 


\section{Acknowledgments}

This work was supported by JSPS KAKENHI Grant Number 25350468.

\section{References}

G. H. Bardy, K. L. Lee, D. B. Mark, et al. (2008), 'Home use of automated external defibrillators for sudden cardiac arrest', New England Journal of Medicine, 2008, Vol. 358, pp. 1793-804. http://dx.doi.org/10.1056/nejmoa0801651

L. Becker, M. Eisenberg, C. Fahrenbruch, L. Cobb (1998), 'Public locations of cardiac arrest implications for public access defibrillation', Circulation, 1998, Vol. 97, pp. 2106-2109. http://dx.doi.org/10.1161/01.cir.97.21.2106

H. Endoh, S. Hida, S. Oohashi, H. Kinosita, Y. Hayashi, N, Saitoh, T. Honda (2011), 'Effective deployment of AEDs targeting sudden cardiac arrest in the home: simulation study using a geographic information system', Journal of Japanese Association for Acute Medicine, 2011, Vol. 22, pp. 1-8. http://dx.doi.org/10.3893/jjaam.22.1

Fire and Disaster Management Agency (1993), 'the implementation guideline about promoting enlightening and dissemination activities of first aid education', Fire and Disaster Management Agency, 1993.

Tokyo Fire Department (2011), 'An opinion poll on firefighting', http://www.tfd.metro.tokyo.jp/yoron/data/27.pdf (accessed on March 19, 2016), Tokyo Fire Department, 2011.

Fire and Disaster Management Agency, Ministry of Internal Affairs and Communications (2015), 'The present condition of emergency rescue, Heisei 27 edition', Fire and Disaster Management Agency, Ministry of Internal Affairs and Communications, 2015, pp. 79-86.

Y. Fujisawaa, T. Hamanob, S. Takegawac (2009), 'Social capital and perceived health in Japan: An ecological and multilevel analysis', Social Science \& Medicine, 2009, Vol. 69, No. 4, pp. 500-505. http://dx.doi.org/10.1016/j.socscimed.2009.05.046

C. Inoue, N. Katahira, N. Hirasawa, A. Fujikawa, Y. liyoshi, C. Takabayashi (2013), 'Social capital and health in Japan: A literature study', The Annual Bulletin of Niigata College of Nursing, ,2013, Vol. 2, pp. 10-15.

Y. Isada, F. Isada (2016), 'A study of performing cardiopulmonary resuscitation by a bystander and social capital', proceedings of 11th International Conference on Science, Health and Medicine, 2016, pp. 511.

Japan Heart Foundation (2016), 'The spread state of AED', http://www.jhf.or.jp/aed/spread.html (accessed on March 19, 2016).

The Japan Medical Association (2011), 'Cardiopulmonary Resuscitation', https://www.med.or.jp/99/ (accessed on January 11, 2016).

N. Kaneya (2008), 'Social capital formation and diverse civil society organizations in Japan: An empirical analysis of the role of neighbourhood associations and nonprofit organizations', The Nonprofit Review, 2008, Vol. 8, No. 1, pp. 13-31. 
B. Kelley (2007), 'Human capital: How what you know shapes your life', The Organisation for Economic Cooperation and Development, 2007, p. 103.

T. Kitamura, T. Iwami, T. Kawamura, K. Nagao, H. Tanaka, A. Hiraide; Implementation Working Group for the All-Japan Utstein Registry of the Fire and Disaster Management Agency (2010), 'Nationwide public-access defibrillation in Japan', The New England Journal of Medicine, 2010, Vol. 362, pp. 994-1004. http://dx.doi.org/10.1056/nejmoa0906644

H. Kondo (2012), 'Research concerning the spread situation of AED', the study report of the Comprehensive Research on Life-Style Related Disease Including Cardiovascular Diseases and Diabetes Mellitus by Health Labour Sciences Research Grant, FY2011 edition, 2012.

T. Mamada (2010), 'Social capital and health studies in Japan: Present and Future', The Bulletin of the Aichi Prefectural University Science of Nursing Department, 2010, Vol. 16, pp. 1-7.

The Ministry of Health, Labour and Welfare (2013), 'Guideline to proper placement of Automated External Defibrillators (AED)' The Ministry of Health, Labour and Welfare, 2013.

H. Mitamura (2008), 'Public access defibrillation: advances from Japan', Nature Clinical Practice Cardiovascular Medicine, 2008, Vol. 5, No. 11, pp. 690-692. http://dx.doi.org/10.1038/ncpcardio1330

H. Mitamura (2012), 'Current state of dissemination, outcome, and future perspective of public access defibrillation in Japan', the Japanese Society of Electrocardiology, 2012, Vol. 32, No. 4, pp. 391-399. http://dx.doi.org/10.5105/jse.32.391

H. Murayama, Y. Fujiwara, I. Kawachi (2014), 'Social capital and health: A review of prospective multilevel studies', Journal of Epidemiology, 2014, Vol. 22, No. 3, pp. 179-187, 2012.

R. Nagatani (2012), 'Relation between social capital, lifestyle and health in the fundamental research of the formation plan of health at Sanyo Onoda', Yamaguchi Medical Science, 2012, Vol. 61, No. 1-2, pp. 31-38.

T. Nieminen, R. Prättälä, T. Martelin, T. Härkänen, M. Hyyppä, E. Alanen, S. Koskinen (2013), 'Social capital, health behaviours and health: A population-based associational study', BMC Public Health, 13, 2013, pp. 613-624. http://dx.doi.org/10.1186/1471-2458-13-613

R. L. Page, S. Husain, L. Y. White, T. D. Rea, C. Fahrenbruch, L. Yin, P. J. Kudenchuk, L. A. Cobb, M. S. Eisenberg (2013) 'Cardiac arrest at exercise facilities: Implications for placement of automated external defibrillators', Journal of the American College of Cardiology, 2013, Vol. 62, No. 22, pp. 2102-2109. http://dx.doi.org/10.1016/j.jacc.2013.06.048

N. Pearce, G. Smith (2003), 'Is social capital the key to inequalities in health?' American Journal of Public Health, 2003, Vol. 93, No. 1, pp. 122-129. http://dx.doi.org/10.2105/AJPH.93.1.122

R. D. Putnam, R. Leonardi, R. Nanetti (1993), Making democracy work: Civic traditions in modern Italy, Princeton University Press, 1993.

L. Rocco, F. Elena, M. Suhrcke (2011), 'From social capital to health - and back', Health Economics, 2011, Vol. 23, No. 5, pp. 586-605. http://dx.doi.org/10.1002/hec.2934

Social Policy Bureau of Cabinet Office (2003), 'White paper on the national lifestyle - social capital: seeking the virtuous circle of rich human relations and civic activities', National Printing Bureau. 2003.

M. Suzuki (2008), 'Social capital and social life: Impact of social capital to a local life', Life Design Report, 2008, Sep.-Oct., pp. 4-15. 